\title{
When is Environmentalism Good for the Environment?
}

\author{
Marco A. Marini ${ }^{1}$ (D) . Ornella Tarola ${ }^{1}$ (D) Jacques-François Thisse ${ }^{2,3}$
}

Accepted: 31 January 2022 / Published online: 3 March 2022 / Published online: 3 March 2022

(C) The Author(s) 2022

\begin{abstract}
We study how the supply of environmentalism, which is defined by psychic benefits (costs) associated with the purchase of high-environmental (low-environmental) qualities, affects the way firms choose their prices and products and the ensuing consequences for the global level of pollution. Contrary to general belief, a high supply of environmentalism does not necessarily give rise to a better environmental outcome because it endows the green firms with more market power which they use to charge higher prices. Nonetheless, environmentalism can be used to effectively complement more traditional policy instruments such as a minimum environmental standard.
\end{abstract}

Keywords Environmentalism · Psychic costs and benefits · Vertical product differentiation $\cdot$ Environmental policy

JEL Classification D11 $\cdot \mathrm{L} 13 \cdot \mathrm{Q} 50$

\section{Introduction}

Most debates about the environmental question take the view that consumers' behavior must change if the world is to transition to a cleaner society. A more deeply rooted environmental consciousness would encourage consumers to shift from brown to green products. The change in individuals' consumption choices would then spark a major drop in emissions. We refer to the various doctrines competing to shape the consumer side as environmentalism, also called green consumerism. The main message of this paper is that environmentalism endows firms with more market power, which in turn affects their incentives

Ornella Tarola

ornella.tarola@uniroma1.it

Marco A. Marini

marco.marini@uniroma1.it

Jacques-François Thisse

jacques.thisse@uclouvain.be

1 Present Address: Department of Social and Economic Sciences, Sapienza Università di Roma, Rome, Italy

2 CORE-UCLouvain, Ottignies-Louvain-la-Neuve, Belgium

3 CEPR, London, United Kingdom 
to supply green products in unsuspected ways. On the one hand, when the best quality product is the green one, a higher supply of environmentalism endows its producer(s) with more market power, which in turn leads to a market outcome that downgrades the ecological footprint because the market share of brown expands. On the other hand, when the high-quality product is the brown one, a stronger environmental ideology permits the entry of less polluting products because the relative quality advantage of the brown firm wanes.

Recently, firms have started paying more attention to the environmental characteristics of their products. A product is now viewed as a bundle of attributes that are hedonic as well as environmental. For example, a car is judged by consumers for its standard performance (safety, comfort, power and reliability) and also for its environmental performance (e.g., its $\mathrm{CO}_{2}$ emissions). It is significant that environmentally friendly firms are often producers of goods with high hedonic attributes. For example, the Group BMW is ranked first in the "Automobiles" category of the Dow Jones Sustainability Index. In Europe, BMW has reduced its $\mathrm{CO}_{2}$ emissions by around 42 percent between 1995 and 2019. Since this company aims to reduce emissions by a further 80 percent by 2030, $\mathrm{BMW}^{\prime} \mathrm{CO}_{2}$ emissions will then be less than 10 percent of what they were in 2006 (Automotive World, November 2020). ${ }^{1}$

To be sure, this trend to align the hedonic and the environmental attributes is relatively recent. For many years, these features were not in sync; the more environmentally friendly goods often came at the expense of high performance. For example, green detergents had lower cleaning performance. Likewise, it took a lot of manual effort to drive the initial prototypes of hybrid and electric vehicles, which were also noisy and uncomfortable. In addition, there were few charging stations and the cars had limited range, two significant drawbacks. In sum, both cases, i.e., the high-quality product is either the green or the brown one, are empirically relevant.

Although the number of empirical papers in environmental economics is sizeable, econometric studies on the consequences of green consumerism are few (Kahn 2007, is a noticeable exception). ${ }^{2}$ This is why we find it meaningful to start with a theory-based investigation. The classical approach in environmental economics is to consider a market in which firms produce a vertically differentiated good-with hedonic and environmental attributes which are both chosen by producers-for consumers who are willing to pay more for the green variants than for the brown. However, this modeling strategy fails to capture the various factors that affect consumer choices in a context where cultural, political and social values interact with standard preferences. That said, as Stigler and Becker (1977) warn, care is needed when considering deviations from standard preferences, for otherwise one runs the risk of providing "microeconomic foundations" to almost any prediction or recommendation policy. We, therefore, consider a minimal deviation from a well-established model by adding individualized psychic costs and benefits to the preferences of rational consumers.

A product has a hedonic (or functional) attribute, which refers, e.g., to the performance of the good, and an environmental attribute, which accounts for the ecological footprint of its production, use, and end of life. Taken together, these two attributes

\footnotetext{
1 In a totally different industry, Kering - a global luxury group managing the development of a series of prestigious houses in fashion, leather goods, jewelry, and watches - is among the top 10 of the most sustainable companies in the world (Corporate Knights' annual Global 100 ranking, 2020).

2 Empirical works suggest the existence of effects consistent with Jevons paradox, as discussed below, which provide some indirect empirical support to our main results (Sorrell 2009; Vivanco 2016).
} 
determine what we call the overall quality of a product. With environmentalism present, the consumer who buys a green product enjoys a psychic benefit, i.e., a non-pecuniary feeling of being a "good citizen." By contrast, when the consumer buys a brown product, she bears a psychic cost, a non-pecuniary feeling of shame or guilt. In doing so, we recognize that an extrinsic component, related to the level of environmentalism in the public sphere, is added to the consumer decision (Kahn 2007; Carlsson et al. 2010). It is noteworthy that qualities are chosen by firms, whereas environmentalism is given to the firms as it is determined on the market for ideas. In our setting, consumers have the opportunity to consume a joint product formed by a private good and an impure public good or bad. Our modeling strategy is thus in the spirit of Andreoni (1995) and Glaeser (2014). Equally important, we recognize that different individuals endorse a value system, here, environmentalism, with variable intensity. As a result, the cost and benefits vary across consumers. In our setting, this heterogeneity is the main source of firms' market power.

Besides its simplicity, our parsimonious modeling strategy allows us to avoid choosing a particular specification among the plethora of justifications underlying pro-environmental preferences (Farrow et al. 2017; Nyborg 2018; van 't Veld, 2020). We see this as a plus for the following reasons. First, we do not have to specify the individual motivations that stand behind those costs and benefits (e.g., warm-glow, identity or conformity). Second, individuals are likely to be heterogeneous in their motivations. Yet, this does not necessarily prevent these motivations to be captured by a simple reduced-form such as ours. Last, because they aim to capture various psychological and sociological considerations, externalities and norms used to study pro-environmental behavior are many and they often have the nature of a black box.

Following the literature, we model the market as the two-stage game in which firms first choose their qualities and, then their prices. Our main findings may then be summarized as follows. First, we consider the price competition stage and show that two cases may arise. In the first one, the high-quality variant is also the green one. When environmentalism is weak, price competition is relatively tough. The brown firm's entry to the market can be deterred by the green firm because consumers are not heterogeneous enough for the green firm to charge a price high enough for the brown firm to enter. As environmentalism grows, however, consumers become more heterogeneous, which provides the green firm with enough market power to set a price sufficiently high to enable the brown firm to sell its product. Once both firms are active, a loftier environmental ideology eases price competition even further so that both firms end up charging higher prices. But, because the green costs grow relatively more than the brown ones, more consumers buy brown than green, which raises the global level of pollution.

In the second case, the green variant is the low-quality product. Environmentalism now generates a greener market outcome because the brown firm uses its market power to charge a price that is sufficiently high for the green firm to supply the consumers who have a high environmental concern. Consequently, whether green consumerism fosters a better ecological market outcome depends on the relative amounts of the environmental attribute embedded in the high-and low-quality products. This difference in results reflects the variations in firms' market power: environmentalism amplifies the high-quality firm's market power when this one is also the green firm whereas it renders the low-quality firm more attractive when this one supplies the green product.

We then turn our attention to the quality game. When the level of environmentalism rises, price competition gets more relaxed and both firms earn higher profits. However, this does not induce both firms to select greener products. The green firm chooses to reduce 
its cost by lowering its quality while the brown firm gains more customers by raising its own. The odd consequence is that the environmental performance of the market outcome decreases when the green product is also the high-quality one. Again, green consumerism leads to an environmental downgrading of the market outcome. Thus, the question posed by the title of the paper may be answered as follows: whereas green consumerism fosters a better environmental outcome when the high-quality product is the brown one, it is detrimental to the environment when the high-quality product is the green one. A higher supply of environmentalism is, therefore, not the panacea that will solve the environmental question.

Last, given the growing number of sectors where a better quality does not come at the expense of the environment, environmentalism cannot be the only weapon that would drastically improve the current level of pollution. In this respect, we agree with Eriksson (2004) who showed that green consumerism cannot replace environmental regulation. When combined with specific policy instruments, environmentalism can deliver its expected positive effects. It is, therefore, crucial to identify those instruments whose effects are, or are not, magnified by green consumerism. We use our baseline model to study the green consumption effects of the two instruments that occupy center stage in policy debates, i.e., a minimum environmental standard and the development of green technologies. First, we show that the health of the environment rises with the minimum standard, even though the green firm becomes less green. In addition, environmentalism and a minimum environmental standard complement each other to yield a more ecological consumption pattern. Second, we find that the use of greener technologies leads to a healthier environment through more eco-friendly qualities and bigger market share for the green variant of the product. Therefore, although augmenting environmentalism with some policy instruments is desirable, not all of them can be combined with green consumerism to give rise to a better ecological outcome.

A last remark is in order. The vertically differentiated oligopoly problem for several products is notoriously hard. In line with the literature, we work with a duopoly as we did not want to sidetrack our analysis with considerations foreign to our main purpose. Yet, it is legitimate to wonder what our main findings would be in a market with more than two firms. We show in the Supplementary Material that a higher level of environmentalism relaxes competition in a way that allows the entry of firms at the low end of the environmental attribute range.

\subsection{Related literature}

When some consumers are willing to pay more to consume less-polluting goods, the analysis of environmental quality is amenable to settings with vertically differentiated products, such as those developed in industrial economics. The entry point of this literature is that environmentally aware consumers perceive products as being vertically differentiated on the basis of their environmental impact. The main message is clear: when consumers care about the ecological footprint of their own consumption, firms segment the market by supplying green and brown variants of the same good, which are sold at high and low prices (see, e.g., Moraga Gonzales and Padron-Fumero, 2002; Rodriguez-Ibeas et al., 2003). In a different strand of literature, consumers internalize partially the environmental damages generated by the consumption of polluting goods (see, e.g., Bansal2003,Amacher2004; Lombardini 2005). The merit of these contributions is to open the door to psychological 
and sociological considerations that are likely to affect the preferences of environmentfriendly consumers.

The idea that competition to attract consumers showing social awareness may lead to worse market outcomes is not new. For example, Dosi and Moretto (2001) show how the use of eco-labelling may lead to a market outcome worse than the situation without ecolabelling, while Garcìa-Gallego and Georgantzìs (2009) find, in a context where firms sell products with different levels of corporate social responsibility, that an increase in social awareness (due for instance to a campaign operated by one or both firms) does not necessarily lead to higher social welfare. In the same vein, Grolleau et al. (2009) show that the presence of consumers with too high a willingness-to-pay for the green product can prevent other consumers from purchasing it, thus leading to a sub-optimal market outcome in terms of environmental performance, while Bonroy and Constantatos (2015) survey the main reasons that may cause eco-labelling to generate undesirable effects. Using a setup that is closer to ours, Deltas et al. (2013) highlight the existence of perverse effects associated with policies that aim to improve the environmental performance of the market outcome. Although this list is not exhaustive, we are not aware of a paper that underscores the role of green consumerism as a value system that affects simultaneously firms' market behavior and consumers' choices.

Note, finally, that our results also point in the same direction as the Jevons paradox, which generates heated debates in environmental economics (Allcott, 2005). According to this paradox, energy-saving policies may increase rather than decrease energy consumption. It is customary in this literature to distinguish between direct and indirect rebound effects. The former is often obtained under a ceteris paribus assumption, whereas the latter accounts for the endogeneity of several variables. In a way, our paper points in the same direction as indirect rebound effects. Indeed, although environmentalism is always desirable at the prevailing prices, this need not be so when it is recognized that firms respond to changes in environmental ideology by choosing strategically new prices and products in an oligopolistic market.

The paper is organized as follows. The model is presented in Sect. 2. Section 3 characterizes the equilibrium of a price subgame. In Sect. 4, we solve the quality game. Section 5 focuses on how the supply of environmentalism affects the environmental surplus generated by the market equilibrium. In Sect. 6, we discuss the combination of environmentalism with a minimum quality standard and the adoption of greener technologies. Section 7 concludes.

\section{The Model}

\subsection{Preferences and Demands}

We consider a market with a unit mass of consumers and two firms. In line with the literature, we assume that the product is indivisible (e.g., a durable) and that each consumer buys one unit of this product (perhaps because this product is an indispensable good), so that the whole market is covered. Full market coverage eliminates any aggregate demand effects from changes in environmentalism, and thus allows us to focus on the purely strategic effects of competition.

The overall quality of a product is determined by both its hedonic and environmental attributes, $a_{h}>0$ and $a_{e}>0$, which are chosen by its producer. In this paper, we remain 
agnostic about how the two attributes interact to determine the quality of a product. More specifically, let $f(\cdot, \cdot)$ be any positive and increasing function in each component and denote by $q_{G}=f\left(a_{h}^{G}, a_{e}^{G}\right)\left(\right.$ resp., $\left.q_{B}=f\left(a_{h}^{B}, a_{e}^{B}\right)\right)$ the quality of the green (resp., brown) variant. The green firm/product $G$ (resp., brown $B$ ) embeds a higher (resp., smaller) amount of environmental attribute than its rival, that is, $a_{e}^{G}>a_{e}^{B}$. Green is the high-quality product when $a_{h}^{i}$ and $a_{e}^{i}$, with $i=B, G$, are such that $f\left(a_{h}^{G}, a_{e}^{G}\right)>f\left(a_{h}^{B}, a_{e}^{B}\right)$. When the opposite inequality holds, brown is the high-quality product. That said, two cases may arise. In the first one, firm $G$, which by definition supplies the green product $\left(a_{e}^{G}>a_{e}^{H}\right)$, is also the high-quality firm $\left(q_{G}>q_{B}\right)$. This occurs when the hedonic attribute of $G$ dominates the hedonic attribute of $B\left(a_{h}^{G}>a_{h}^{B}\right)$ or when the hedonic attribute of $B$ is not strong enough to compensate for its environmental disadvantage $\left(a_{h}^{B}>a_{h}^{G}\right.$ and $\left.f\left(a_{h}^{G}, a_{e}^{G}\right)>f\left(a_{h}^{B}, a_{e}^{B}\right)\right)$. In the second case, the hedonic quality of $B$ is sufficiently high for the overall quality of the brown product to exceed that of the green product, i.e., $a_{h}^{B}>a_{h}^{G}$ and $q_{B}>q_{G}$. The bulk of the paper focuses on the case where the green product embodies more hedonic attribute than the brown one, i.e., $a_{h}^{G}>a_{h}^{B}$. However, we will also briefly discuss the opposite case that retains (declining) empirical relevance.

Each product pertains to a reference group to which a consumer relates, or aspires to relate, herself through the product she consumes. The reference group is formed here by those consumers who buy the green product. Belonging to this group confers a psychic benefit to its members that translates into a higher utility. This psychic benefit $\psi_{G}>0$ is the concrete form taken by the impact of environmentalism on individual preferences. By contrast, a consumer who buys brown suffers a negative effect - under the form of shame or guiltiness - that reduces her welfare. This is because buying a polluting product is perceived as a negative action that excludes her from the reference group. Consequently, the psychic cost $\psi_{B}<0$ the consumer bears makes her worse off. Like the psychic benefit, it is individual-specific. Since the attitude of individuals toward the group(s) they belong to remains a contentious issue, we assume that the psychic costs and benefits are independent of the size of the group. ${ }^{3}$

Let $\beta \geq 0$ be the parameter that measures the intensity of what we call environmental ideology. It is noteworthy that the value of this parameter is independent of the qualities $q_{G}$ and $q_{B}$ chosen by firms. However, how consumers react to this value system depends on the individual. That said, preferences are as follows:

$$
V(\theta)=\left\{\begin{array}{l}
q_{G}+\beta \theta-p_{G}, \\
q_{B}-\beta \theta-p_{B} .
\end{array}\right.
$$

The heterogeneity parameter $\theta$ measures the impact of green consumerism on a consumer's preferences. Indeed, the psychic benefits and costs of $\theta$-consumer are given, respectively, by $\psi_{G}=\beta \theta$ and $\psi_{B}=-\beta \theta$. In line with the literature we assume that $\theta$ is uniformly distributed over the interval $[0,1]$. Things thus work as if a $\theta$-consumer were to pay the price $p_{G}-\beta \theta$, which is smaller than the market price, for the green product and $p_{B}+\beta \theta$, which is higher than the market price, for the brown. These prices are consumer-specific and also vary with the supply of environmentalism. Since a higher supply of environmentalism

\footnotetext{
${ }^{3}$ Note that (2) also holds when consumers care about the size of the group they belong to, i.e., when $\theta$ is replaced by $\theta n_{G}$ with $n_{G}=(1-\bar{\theta})$ for the green consumers and by $\theta n_{B}$ where $n_{B}=\bar{\theta}$ for the brown one. That is, the green consumers feel better when their group is bigger, while the brown consumers feel worse. See Brécart (2013) for a related approach.
} 
makes the greens better-off and the browns worse-off, the environmental ideology $\beta$ affects consumers' willingness-to-pay, hence firms' behavior. Clearly, a consumer characterized by a higher $\theta$ has a higher willingness-to-pay for green and a lower one for brown. Note also that our results hold true if $\theta$ is distributed over $[0, \Theta]$ where $\Theta$ measures the spread of consumers' ideological heterogeneity. It is then sufficient to replace $\beta$ by $\beta / \Theta$ for $\theta$ to vary in $[0,1]$. Hence, a higher (resp., lower) $\beta$ also means that consumers are more (resp., less) heterogeneous. Given this normalization, a high or a low value of $\beta$ should not be interpreted in a restrictive way as it may also reflect the heterogeneity of the population.

Although it seems a priori natural to consider a two-dimensional setting in which consumers are heterogeneous in their attitude toward quality $q_{i}$ and environmentalism $\beta$, we have chosen not to do it. First, these models are especially interesting when firms select the two attributes. This is not the case here as $\beta$ is exogenous to firms. Furthermore, the few attempts made to develop such models show that working with those settings becomes quickly very cumbersome from the analytical point of view, which explains why the number of contributions is few (Irmen and Thisse 1998; Lauga and Ofek, 2011). Since our main focus is to study the role of idiosyncratic consumers' adherence to environmentalism as a value system, we find it reasonable to assume that consumers are heterogeneous in their attitude toward green consumerism while assuming with Garella and Lambertini (2014) that they are homogeneous about the quality of products. Formally, the taste distribution about quality is atomic. ${ }^{4}$

Substituting (1) into $V_{G}(\theta)=V_{B}(\theta)$ and solving for $\theta$ yields the consumer $\bar{\theta}$ indifferent between buying $G$ or $B$ at prices $p_{G}>0$ and $p_{B}>0$ :

$$
\bar{\theta}=\frac{\left(p_{G}-p_{B}\right)-\left(q_{G}-q_{B}\right)}{2 \beta} .
$$

How consumers are allocated between green and brown thus depends on the price gap $p_{G}-p_{B}$ and the quality gap $q_{G}-q_{B}$. When $\bar{\theta}>0$, at given prices and qualities, a loftier environmental ideology leads more consumers to buy green because $\bar{\theta}$ decreases when $\beta$ increases. This is precisely the effect expected by many activists and NGOs. Regardless of the sign of $q_{G}-q_{B}$, the consumers in the high end of the environmental attribute range always choose the green product. Nevertheless, a higher $\beta$ has a weaker (resp., stronger) impact on $\bar{\theta}$ when $q_{G}-q_{B}>0$ (resp., $q_{G}-q_{B}<0$ ) because the green product has a large (resp., small) market share. Therefore, it is harder (resp., easier) for the green firm to gain customers at the expense of the brown one.

In (2), we implicitly assume that the marginal consumer $\bar{\theta}$ belongs to the open interval $(0,1)$. However, it should be clear that the right-and-side of (2) may be smaller than 0 or larger than 1. Consequently, the equilibrium value of $\bar{\theta}$ that must be used to determine firms' market demands $D_{G}=1-\bar{\theta}$ and $D_{B}=\bar{\theta}$ are given by the following expression:

$$
\bar{\theta}\left(p_{G}, p_{B} ; q_{G}, q_{B}\right)=\max \left\{0, \min \left\{\frac{\left(p_{G}-p_{B}\right)-\left(q_{G}-q_{B}\right)}{2 \beta}, 1\right\}\right\},
$$

so that either both demands are positive or a single firm supplies the entire market.

\footnotetext{
4 We have studied price competition in a duopoly in which consumers are heterogeneous along with both the product quality and the environmental ideology. The results are similar to those obtained in Sect. 3 .
} 
Note that our approach is consistent with Andreoni's (1990) idea of "warm-glow satisfaction" associated with the selfish pleasure derived from "doing good", while doing the bad thing bears no stigma (see also Ambec and De Donder 2021). To see it, we rewrite (1) as follows:

$$
V(\theta)=\left\{\begin{array}{c}
q_{G}+\beta \theta-p_{G}, \\
q_{B}-p_{B},
\end{array}\right.
$$

so that our results remain valid provided that $\beta$ is replaced throughout by $\beta / 2$.

\subsection{Production Costs and Overhead Expenses}

Let us now come to firms' cost. We assume that firms can improve the ecological footprint of their products, without scarifying the hedonic attribute, which is kept fixed. The firms' choice of a better environmental quality gives rise to specific expenditures, such as R\&D and capital goods, which typically have the nature of endogenous overhead expenditures. Therefore, it seems reasonable to assume that most of the burden of quality improvement falls on fixed costs $F(q)$ (Ronnen, 1991; Motta 1993). Nevertheless, marginal production costs, which are constant with respect to output, are likely to increase with quality because producing a better environmental quality without changing the product's performance typically requires more expensive inputs (Crampes 1995; Lauga and Ofek, 2011).

Since the improvement of the environmental quality is likely to require more investment in R\&D and capital, the function $F$ is also strictly convex in $q$. In line with the literature, we assume that fixed costs are quadratic in $q$, i.e., $F(q)=q^{2} / 2$. We also assume that the quality marginal cost is proportional to the chosen quality, i.e., $c q$ where $c$ is a positive constant. In what follows, we assume that both firms have access to the same technology described by the cost function $C(q)=c q+q^{2} / 2$.

Finally, we assume that the green firm bears some overhead expenditure $H$, such as those required to certify the amount of environmental attribute embodied in its product under the form of eco-labelling (Amacher et al. 2004; Yenipazarli 2015). Likewise, as consumers seem reluctant to the adoption of new technologies that are considered as unproved or hard to check, one may expect the green firm to invest more in advertising to promote its eco-label (Egbue and Long 2012; Millner and Ollivier, 2016).

Profit functions are then defined as follows:

$$
\begin{aligned}
& \pi_{G}\left(p_{G}, p_{B} ; q_{G}, q_{B}\right)=\left(p_{G}-c q_{G}\right) D_{G}\left(p_{G}, p_{B} ; q_{G}, q_{B}\right)-\frac{q_{G}^{2}}{2}-H, \\
& \pi_{B}\left(p_{G}, p_{B} ; q_{G}, q_{B}\right)=\left(p_{B}-c q_{B}\right) D_{B}\left(p_{G}, p_{B} ; q_{G}, q_{B}\right)-\frac{q_{B}^{2}}{2} .
\end{aligned}
$$

Competition between firms is modeled as a two-stage game. At the first stage, firms choose the ecological footprint of their products, which determines the overall quality of their product along the spectrum of technologically feasible qualities given by the interval $[0, \bar{q}]$. At the second stage, firms compete in prices with $p_{G} \geq c q_{G}$ and $p_{B} \geq c q_{B}$. The fixed costs and are sunk at the price competition stage of the game. The market outcome is given by a subgame perfect Nash equilibrium. For this equilibrium to be consistent with the above demand functions, it must be that $q_{G}>q_{B}$. As usual, the game is solved by backward induction. 
Let us make a pause to make it precise what we mean by vertical and horizontal product differentiation. The distinctive feature of the vertical differentiation is the "finiteness property," which states that the number of firms that can survive in equilibrium depends on the degree of heterogeneity across consumers (Shaked and Sutton 1983; Anderson et al. 1992; Lahmandi-Ayed 2007). When marginal costs are equal across products, the unanimous ranking is sufficient for this property to hold, and thus to define vertical differentiation. Here, marginal costs vary with the quality of products. This is why we need a definition that accounts for both preferences and technology. Since the marginal production cost of quality $q$ is $c q$, the expression $q-c q=(1-c) q$ stands for the social value of that quality, the finiteness property holds if and only if all consumers agree on the ranking of all products when each quality $q$ is priced at its marginal cost $c q$. Otherwise, like in horizontal product differentiation, a firm can always sell its output to the consumers who rank its product first because these consumers are willing to pay a price that slightly exceeds the product's marginal cost. Note that $c<1$ must hold for the social value of quality $q$ to be positive.

Since $q_{G}>q_{B}$, all consumers prefer green to brown when $p_{i}=c q_{i}$ if and only if

$$
q_{G}+\beta \theta-c q_{G}>q_{B}-\beta \theta-c q_{B}
$$

holds for all $\theta \in[0,1]$. The most binding condition arises at $\theta=0$, which means $(1-c)\left(q_{G}-q_{B}\right)>0$. For this to hold, it must be that $c<1$. In this case, we may conclude that our model is a vertical differentiation setting. But what happens when $q_{B}>q_{G}$ ? Then, we have $q_{B}(1-c)>q_{G}(1-c)$, which means that consumers at $\theta=0$ prefer $B$ to $G$ when these products are priced at marginal costs. Two cases may arise. In the first one, the consumers at $\theta=1$ are such that $q_{G}(1-c)+\beta<q_{B}(1-c) q_{B}-\beta$ or, equivalently, $\left(q_{B}-q_{G}\right)(1-c)>2 \beta$. Hence, we still have a vertical differentiation setting because the quality difference is large enough for all consumers to prefer $B$ to $G$ when products are priced at marginal costs. As a result, $B$ is able to drive $G$ out of business. In the second case, if $\left(q_{B}-q_{G}\right)(1-c)<2 \beta$ holds, the model becomes hybrid in that the consumers at $\theta=0$ always remains loyal to $B$ while those at $\theta=1$ always prefer $G$ to $B$, like in a model of horizontal differentiation. In this case, both firms are active at the price equilibrium. In sum, for a given quality difference $q_{B}-q_{G}>0$, a low level of environmentalism does not affect the vertical differentiation nature of our setting. By contrast, a high level endows it with a horizontal differentiation structure.

To sum up, when the two conditions $q_{G}<q_{B}$ and $\left(q_{B}-q_{G}\right)(1-c)<2 \beta$ hold, one can think of our model as a blend of horizontal and vertical differentiation where the parameter $\beta$ would play the role of the unit transportation cost. ${ }^{5}$ In this case, our setting would belong to the hybrid class of models where firms are located at the endpoints of a linear segment and produce vertically differentiated goods, such as those considered by Brekke et al. (2006) and Deltas et al. (2013). Though ingenious, this analogy is misleading because a higher transportation rate affects all consumers negatively because it measures consumers' loyalty to the nearer product, whereas a stronger environmental ideology has a positive impact on the consumers who buy green but a negative impact on those who buy brown. More importantly, this analogy is valid only in the special case where the inequalities $q_{G}<q_{B}$ and $\left(q_{B}-q_{G}\right)(1-c)<2 \beta$ are satisfied.

${ }_{5}^{5}$ We thank a referee for this suggestion. 


\section{How does Price Competition Affect the Consumption of the Green and Brown Products?}

In order to determine how environmentalism affects firms' behavior and the level of pollution generated by the consumption of goods differentiated by their environmental qualities, we need a benchmark case that describes the market outcome when consumers' choices are unaffected by social considerations, i.e., $\beta=0$.

\subsection{Price Competition in the Absence of Environmentalism}

By setting $\beta=0$ in (1), we obtain the benchmark case in which consumers care only about their own choices. We have a standard setting in which two firms selling a vertically differentiated product and producing at different marginal costs compete in prices. Studying the case where $\beta=0$ is worth doing because it allows us to determine how the market outcome is affected by environmentalism.

Since consumers are homogeneous when $\beta=0$, firms compete in prices under different marginal costs. Consequently, they undercut each other until one firm reaches its marginal cost. In the presence of a price tie, it is natural to assume that the price tie is broken in favor of the firm with the lower marginal cost since this firm is able to lower its price further. Since all consumers prefer to buy $G$ when both products are priced at their marginal costs, firm $G$ can undercut firm $B$ until its price is equal to

$$
p_{G}^{*}\left(q_{G}, q_{B}\right)=q_{G}-(1-c) q_{B}>c q_{G},
$$

while $p_{B}^{*}\left(q_{G}, q_{B}\right)=c q_{B}$, and thus the green firm supplies the entire market. The above pair of prices is a Nash equilibrium of the price subgame.

Thus, in the absence of environmentalism $(\beta=0)$, all consumers buy from the green firm, which sets a price above its marginal cost. This firm sets a price such that consumers are indifferent between the two products, whereas the other firm prices at marginal cost. This shows the main implication of using an atomic distribution for quality: assuming that consumers are heterogeneous in their quality valuation will make it possible to have an equilibrium in which both firms share the market and earn positive profits (see the references cited in the introduction). We show below that this is what happens when the environmental ideology becomes strong enough or when the population is sufficiently heterogeneous.

\subsection{Price Competition in the Presence of Environmentalism}

Whereas $q_{G}$ and $q_{B}$ are the qualities chosen by firms, a consumer considers the following "subjective" qualities that depend on her type $\theta$ and the supply of environmentalism $\beta$ :

$$
Q_{G}(\theta) \equiv q_{G}+\beta \theta>q_{G} \quad Q_{B}(\theta) \equiv q_{B}-\beta \theta<q_{B} .
$$

Observe that the qualities $q_{G}$ and $q_{B}$ are firm-specific, while the subjective qualities $Q_{G}(\theta)$ and $Q_{B}(\theta)$ are both firm- and consumer-specific. This difference is a distinctive feature of our model. In addition, raising $\beta$ means that $Q_{G}$ increases whereas $Q_{B}$ decreases, even when $q_{G}$ and $q_{B}$ do not change. So, everything else, a higher environmental concern strengthens the market power of the green firm relative to the brown firm by magnifying the quality difference $q_{G}-q_{B}$. 
A price equilibrium $\left(p_{1}^{*}, p_{2}^{*}\right)$ is interior when both firms share the market $\left(0<\bar{\theta}\left(p_{1}^{*}, p_{2}^{*}\right)<1\right)$ and make positive profits. Since the profit function $\pi_{i}$ is concave in $p_{i}$, applying the first-order condition yields the following equilibrium prices:

$$
\begin{aligned}
& p_{G}^{*}\left(q_{G}, q_{B}\right)=\frac{1}{3}\left(c\left(2 q_{G}+q_{B}\right)+\left(q_{G}-q_{B}\right)+4 \beta\right), \\
& p_{B}^{*}\left(q_{G}, q_{B}\right)=\frac{1}{3}\left(c\left(q_{G}+2 q_{B}\right)-\left(q_{G}-q_{B}\right)+2 \beta\right) .
\end{aligned}
$$

Whereas $p_{G}^{*}\left(q_{G}, q_{B}\right)>c q_{G}$ always holds, $p_{B}^{*}\left(q_{G}, q_{B}\right)>c q_{B}$ if and only if $\beta>\beta_{G} \equiv(1-c)\left(q_{G}-q_{B}\right) / 2$, that is, the intensity of green consumerism is sufficiently strong or, equivalently, when consumers are sufficiently heterogeneous in their attitude toward environmentalism. Otherwise, as both prices $p_{G}^{*}$ and $p_{B}^{*}$ decrease when $\beta$ gets smaller, when $\beta<\beta_{G}$ firm $G$ charges the limit price $p_{G}^{*}=c q_{B}+\left(q_{G}-q_{B}\right)$, which is such that firm $B$ to remain out of business when it prices its variant at marginal cost $c q_{B}$. Such an equilibrium typically arises in vertical differentiation models when consumer heterogeneity is low; it illustrates the finiteness property discussed above (Gabszewicz and Thisse 1979). Assume now that $\beta>\beta_{G}$, so that firms $G$ and $B$ share the market. In this case, both prices increase with the intensity of environmental ideology $(\beta \uparrow)$ because psychic costs and benefits rise. Stated differently, environmentalism relaxes competition at the price stage. What is more, the green firm's price grows faster than the brown firm's with $\beta$ because a stronger environmental ideology renders the green product even more attractive because $Q_{G}-Q_{B}$ becomes wider. Furthermore, when $q_{G}>q_{B}$, a higher environmental concern leads the green firm to increase its price to such an extent that even the brown can follow suit as the two equilibrium prices increase with $\beta$.

Furthermore, the price differential is given by

$$
p_{G}^{*}\left(q_{G}, q_{B}\right)-p_{B}^{*}\left(q_{G}, q_{B}\right)=\frac{1}{3}\left((2+c)\left(q_{G}-q_{B}\right)+2 \beta\right)>0 .
$$

Hence, a wider quality gap leads to a wider price differential because $p_{G}^{*}$ increases while $p_{B}^{*}$ decreases with $q_{G}-q_{B}{ }^{6}$ Plugging $p_{G}^{*}\left(q_{G}, q_{B}\right)$ and $p_{B}^{*}\left(q_{G}, q_{B}\right)$ into (3), we get the following expression for the marginal consumer at the equilibrium prices:

$$
\bar{\theta}\left(q_{G}, q_{B}\right)=\frac{1}{3}-\frac{(1-c)\left(q_{G}-q_{B}\right)}{6 \beta} .
$$

Thus, $\bar{\theta}\left(q_{G}, q_{B}\right)$ is a continuous function of $\left(q_{G}, q_{B}\right)$. Regardless of the sign of $q_{G}-q_{B}$, the green firm supplies the high end of the market, i.e., its demand is equal to $\left(1-\bar{\theta}\left(q_{G}, q_{B}\right)\right)$ while the brown firm serves the low end, i.e., its demand is given by $\bar{\theta}\left(q_{G}, q_{B}\right)$. The market share of firm $G$ is always larger than $2 / 3$ when this firm supplies the high-quality variant while its market share is always smaller than $2 / 3$ otherwise. When $q_{G}-q_{B}>0$ (resp.,

\footnotetext{
${ }^{6}$ We are now equipped to shed more light on the differences between our setting and Deltas et al. (2013). Denoting by $\beta$ the unit transportation cost $\theta$ in their model, their equilibrium prices are given by $\hat{p}_{G}\left(q_{G}, q_{B}\right)=\left(c\left(2 q_{G}+q_{B}\right)+\beta\left(q_{G}-q_{B}\right)+4 \beta\right) / 3$ and $\hat{p}_{B}\left(q_{G}, q_{B}\right)=\left(c\left(q_{G}+2 q_{B}\right)-\beta\left(q_{G}-q_{B}\right)+2 \beta\right) / 3$. Despite similarities with (4), it is clear that $\beta$ does not play the same role in the price vectors $\left(p_{G}^{*}, p_{B}^{*}\right)$ and $\left(\hat{p}_{G}, \hat{p}_{B}\right)$. More importantly, $\beta$ affects the marginal consumer, hence the demands in the quality game, in opposite directions when $q_{G}>q_{B}$. This shows once more that the parameter $\beta$ used here cannot be interpreted as the unit transportation cost in a hybrid model that combines vertical and horizontal differentiation. In Brekke et al. (2006), prices are regulated and exogenous. This does not permit the comparison of results.
} 
$q_{G}-q_{B}<0$ ), a stronger environmental ideology allows the green firm to enjoy a wider (resp., narrower) market share.

\subsection{The Impact of Environmental Ideology on Market Prices}

When $\beta<\beta_{G}$, we have seen that firm $G$ serves the whole market. When $\beta$ increases, we still have $\bar{\theta}\left(q_{G}, q_{B}\right)=0$ until the threshold $\beta_{G}$ is reached where the consumers at $\theta=0$ are indifferent between the two products. When $\beta$ rises above $\beta_{G}$, both the psychic benefits of the greens and the psychic costs of the brown rise. As shown by (6), $\bar{\theta}\left(q_{G}, q_{B}\right)$ becomes positive. Therefore, product $B$ is sold to the consumers belonging to $\left[0, \bar{\theta}\left(q_{G}, q_{B}\right)\right]$. Why do some consumers now choose to buy the brown product? As $\beta$ increases, both prices increase but $p_{G}^{*}$ increases faster than $p_{B}^{*}$. When the price gap is wide enough, this induces the low $\theta$-consumers to buy $B$. In other words, a sufficiently strong environmental ideology allows the brown product to enter the market. By implication, a more environmentfriendly population ends up with a worse ecological footprint, the reason being that this social motivation exacerbates the perceived quality difference $Q_{G}-Q_{B}$, which in turn leads firm $G$, hence firm $B$, to charge higher prices. ${ }^{7}$ Note, however, that the green firm always supplies at least $2 / 3$ of the market because its product is both the high-quality and the green variant.

It may be hard to think of a market that is fully served by the green firm and that, as a result of environmental concern, becomes a market served by two firms because a brown firm enters. Yet, this result is essentially the same as what we observe in a market where consumers get richer, which leads the high-quality firm to charge a higher price, thus allowing the entry of a low-quality, but cheaper, product. For example, think of the cosmetic industry (Kiko Milano vs Chanel) or the fashion sector (Zara vs Gucci).

The next proposition provides a summary.

Proposition 1 Assume that $q_{G}>q_{B}$. When the degree of environmental ideology is low or the population is fairly homogeneous - the brown firm cannot enter the market. However, a sufficiently high value of $\beta$ or, equivalently, a very heterogeneous population, leads to a higher level of pollution through the entry of the brown firm. Once this firm is in business, increasing $\beta$ raises the level of pollution because fewer consumers buy green.

This proposition result shows that a social attitude that seems beneficial to the environment may generate perverse effects by raising the market power of the green-highquality firm disproportionately. More specifically, this firm takes advantage of the growing psychic benefits associated with the consumption of the green product to raise its price at a level sufficiently high for the brown firm to enter the market or for more consumers to buy brown, even though the psychic costs associated with the consumption of brown also increase.

Proposition 1 relies on the assumption $q_{G}>q_{B}$ in a way that is worth stressing. To this end, we now assume that brown has the quality advantage, that is, $q_{B}>q_{G}$. Since the marginal consumer is still given by (3), the demand system remains the same because the consumers who buy green (if any) are characterized by high values of

\footnotetext{
7 Note also that this price escalation tends to reduce consumers' real income, which may incite them to buy cheap, but dirty, goods on other markets.
} 
$\theta$. Thus, at an interior price equilibrium, the market prices are still given by (4) but where $q_{G}-q_{B}<0$. That said, we have seen in Sect. 2 that two cases must be considered according to the strength of the environmental ideology. In the first one, we have $\beta_{B} \equiv\left(q_{B}-q_{G}\right)(1-c) / 2<\beta$. The brown firm thus remains the only supplier provided that $\beta<\beta_{B}$. In other words, the quality gap is too narrow to permit the entry of green. The brown firm thus finds it profit-maximizing to charge the limit price $p_{B}^{*}=c q_{G}+\left(q_{B}-q_{G}\right)$ because $p_{G}^{*}=\left(c\left(q_{B}+2 q_{G}\right)-\left(q_{B}-q_{G}\right)+2 \beta\right) / 3<c q_{G}$. This inertia in the market outcome may explain why only the brown product is available when a mild environmental concern prevails and when the quality of green is lower than that of brown, as discussed in the introduction.

In the second case, $\beta$ crosses $\beta_{B}$ from below, the green product enters the market from above and charges a price given by (4), which is such that $p_{G}^{*}=\left(c\left(q_{B}+2 q_{G}\right)-\left(q_{B}-q_{G}\right)+2 \beta\right) / 3>c q_{G}$. In other words, the consumers with the highest environmental concern shift from brown to green. However, the brown firm may build on its quality advantage to charge a price higher than the green firm. Nevertheless, when $\beta>(2+c)\left(q_{B}-q_{G}\right) / 2>\beta_{B}$, the intensity of environmentalism becomes sufficiently strong for the green firm to set a price higher than its rival. In other words, green consumerism reverses, at least to some extent, the quality advantage of firm $B$. Since (6) remains valid, we may conclude as follows: despite the quality disadvantage of the green product, environmentalism allows the corresponding firm to capture a growing market share. In other words, more environmentalism incentivizes consumers to buy green when the quality of brown is higher than that of green. Yet, green cannot drive brown out of business because its market share is bounded above by $1 / 3$. This is to be contrasted with what we have seen when $q_{G}>q_{B}$ where green is always able to secure the entire market. Or, to put it differently, brown always captures a positive market share because we are now in a context akin to a horizontal differentiation model.

This difference in results should not come as a surprise. In Proposition 1, the highquality firm is also the green one. This endows this firm a great deal of market power, which it exploits by charging a very high price. By contrast, that the high-quality firm is the brown one reduces its market power. Therefore, this firm must decrease its price because competition is tougher, which leads the low-quality, but green firm, to attract more customers through an even lower price and higher psychic costs and benefits.

The above discussion shows that several cases may arise in the quality game. For this reason, we will focus in what follows on the relevant case where $q_{G}>q_{B}$, that is, there is vertical differentiation.

The n-firms case. Before studying quality competition, it is worth stressing that Proposition 1 is not an artefact of our assumption to work with a duopoly. To illustrate, we consider $n \geq 2$ firms whose environmental qualities are given by $q_{k}=k q$ for $k=1, \ldots, n$ and $q>0$ (in the 2-firm case considered above, we have $q_{G}=q_{2}$ and $q_{B}=q_{1}$ ). For analytical simplicity, we also assume that $c=0$. The following proposition is then proved in the Supplementary Material.

Proposition 1a There exist $n-1$ thresholds $\beta_{1}>\ldots>\beta_{k}>\ldots>\beta_{n-1}$ such that firm kis active if and only if $\beta>\beta_{k}$ for $k=1, \ldots, n-1$. Furthermore, when $\beta$ increases, the active firms charge higher prices.

Thus, as the environmental ideology spreads, firms enter sequentially from high to low environmental qualities because the incumbents enjoy more market power. 


\section{The Environmental Qualities Supplied by the Market}

We may wonder whether Proposition 1 is caused by the assumption of exogenous environmental qualities. In other words, quality competition could lead to a better environmental outcome? To answer this question, we must determine how firms choose their qualities in a strategic context. We now turn our attention to the first stage of the game. Since our focus is mainly on the environmental impact of the goods, we assume that firms invest only in the environmental attribute of their goods. In other words, increasing the quality $q_{i}$ amounts to raising the level of the environmental attribute $a_{e}^{i}$ of product $i$.

Duopoly models of vertical differentiation are characterized by interior equilibria where the two firms share the market or by corner equilibria where the high-quality firm secures the entire market. In what follows, we focus on the more relevant case of interior equilibria.

\subsection{The Equilibrium Qualities}

A quality equilibrium $\left(q_{G}^{*}, q_{B}^{*}\right)$ is interior if and only if $\bar{\theta}\left(q_{G}^{*}, q_{B}^{*}\right) \in(0,1)$ when $q_{G}^{*}>q_{B}^{*}$. Assume for the moment that such an equilibrium exists.

Plugging the equilibrium prices (4) into firms' profit functions yields the payoffs of the first-stage game:

$$
\begin{aligned}
& \pi_{G}^{*}\left(q_{G}, q_{B}\right)=\frac{\left[4 \beta+k^{1 / 2}\left(q_{G}-q_{B}\right)\right]^{2}}{18 \beta}-\frac{1}{2} q_{G}^{2}-H, \\
& \pi_{B}^{*}\left(q_{G}, q_{B}\right)=\frac{\left[2 \beta-k^{1 / 2}\left(q_{G}-q_{B}\right)\right]^{2}}{18 \beta}-\frac{1}{2} q_{B}^{2},
\end{aligned}
$$

where $k \equiv(1-c)^{2}>0$. Since the function $\pi_{i}$ is quadratic in $q_{i}$, then $\pi_{i}$ is strictly concave in $q_{i}$ if and only if the coefficient of $q_{i}^{2}$ in (7) is negative, that is

$$
\beta>\frac{k}{9} \text {. }
$$

In this case, the function $\pi_{i}$ is continuous, strictly concave and tends to $-\infty$ when $q_{G} \rightarrow \infty$. The first-order conditions with respect to qualities yield the following best-reply functions:

$$
q_{G}^{*}\left(q_{B}\right)=\max \left\{0, \frac{k^{1 / 2}\left(4 \beta-k^{1 / 2} q_{B}\right)}{9 \beta-k}\right\}, \quad q_{B}^{*}\left(q_{G}\right)=\max \left\{0, \frac{k^{1 / 2}\left(2 \beta-k^{1 / 2} q_{G}\right)}{9 \beta-k}\right\} .
$$

When (8) holds, qualities are strategic substitutes, that is, when a firm increases (resp., decreases) the environmental quality of its product, its rival finds it profit-maximizing to decrease (resp., increase) its own quality.

Choosing a minimum positive quality makes some of the expressions derived below more cumbersome. For notational simplicity, we then assume without loss of generality that the minimum quality is given by 0 . The choice of an upper bound $\bar{q}$ of the strategy space in a quality game is often a delicate issue. Here, we can use (9) to determine $\bar{q}$ endogenously as follows:

$$
\bar{q} \equiv q_{G}^{*}(0)=\frac{4 k^{1 / 2} \beta}{9 \beta-k}>0
$$


The candidate equilibrium qualities are obtained by solving the system of linear equations (9) whose unique solution is:

$$
q_{G}^{*}=\frac{2 k^{1 / 2}}{3} \frac{6 \beta-k}{9 \beta-2 k}, \quad q_{B}^{*}=\frac{2 k^{1 / 2}}{3} \frac{3 \beta-k}{9 \beta-2 k} .
$$

We now check that the (10) satisfies the above-mentioned three conditions that define an interior equilibrium. First, it is readily verified that $q_{G}^{*}>q_{B}^{*}$ if and only if

$$
\beta>\frac{2 k}{9}
$$

holds, while $q_{B}^{*}>0$ if and only if

$$
\beta>\frac{k}{3}
$$

Moreover, we have $q_{G}^{*}<\bar{q}$ because $q_{B}^{*}>0$.

Second, the marginal consumer (6) at (10) is such that

$$
\bar{\theta}\left(q_{G}^{*}, q_{B}^{*}\right)=\frac{3 \beta-k}{9 \beta-2 k} .
$$

It is readily verified that $0<\bar{\theta}<1$ always holds when (12) holds.

Third, substituting (10) in (4), we obtain the equilibrium markups and profits:

$$
p_{G}^{*}\left(q_{G}^{*}, q_{B}^{*}\right)-c q_{G}^{*}=\frac{2 \beta(6 \beta-k)}{9 \beta-2 k}, \quad p_{B}^{*}\left(q_{G}^{*}, q_{B}^{*}\right)-c q_{B}^{*}=2 \beta \frac{3 \beta-k}{9 \beta-2 k},
$$

and

$$
\pi_{G}^{*}\left(q_{G}^{*}, q_{B}^{*}\right)=\frac{2}{9} \frac{(6 \beta-k)^{2}(9 \beta-k)}{(9 \beta-2 k)^{2}}-H \quad \pi_{B}^{*}\left(q_{G}^{*}, q_{B}^{*}\right)=\frac{2}{9} \frac{(3 \beta-k)^{2}(9 \beta-k)}{(9 \beta-2 k)^{2}},
$$

which are all positive by implication of (12).

Clearly, (12) is more stringent than (8) and (11). Therefore, the conditions (12) must hold for (10) to be an interior equilibrium of the quality game. Note that the green firm earns higher profits than the brown firm when the certification cost $H$ is not too high.

It remains to verify that firms $G$ and $B$ have no unilateral incentive to deviate from (10). We show in Appendix A that it is never profitable for firm $G$ to choose a quality smaller than $q_{B}^{*}$ if $H<H_{\max }$, where $H_{\max }$ is defined by (A.4) in Appendix A. Indeed, when the certification cost is high, no firm wants to be the green firm. Furthermore, firm $B$ has no incentive to choose a quality larger than $q_{G}^{*}$ if $H>H_{\min }$, where $H_{\min }$ is given by (A.2) in Appendix A. Indeed, when the certification cost is low, both firms want to be the green firm. Finally, it is shown in the appendix that the inequality $H_{\min }<H_{\max }$ always holds.

The following proposition summarizes the above findings.

Proposition 2 If $\beta>k / 3$ and $H_{\min } \leq H \leq H_{\max }$, there exists a unique interior subgame perfect Nash equilibrium where the green firm is the high-quality firm. At this equilibrium, the green firm has a bigger market share and earn higher profits than the brown firm. If $H>H_{\max }$ or $H<H_{\min }$, there exists no interior quality equilibrium with $q_{G}^{*}>q_{B}^{*}$. 
When $\beta<k / 3$, the market outcome involves a corner solution in which at least one firm chooses the minimum quality.

\subsection{How the Environmental Ideology Affects firms' Qualities?}

In what follows, we study the effect of a change in $\beta$, which captures the population's environmental ideology, on the market outcome.

Assume first that $\beta>k / 3$. Totally differentiating the first-order conditions for the equilibrium qualities with respect to $\beta$ yields the following expressions:

$$
\begin{aligned}
& \operatorname{sign} \frac{\mathrm{d} q_{G}^{*}}{\mathrm{~d} \beta}=\operatorname{sign} \frac{\partial^{2} \pi_{G}^{*}\left(q_{G}^{*}, q_{B}^{*}\right)}{\partial \beta \partial q_{G}}=\operatorname{sign}\left(q_{B}^{*}-q_{G}^{*}\right), \\
& \operatorname{sign} \frac{\mathrm{d} q_{B}^{*}}{\mathrm{~d} \beta}=\operatorname{sign} \frac{\partial^{2} \pi_{B}^{*}\left(q_{G}^{*}, q_{B}^{*}\right)}{\partial \beta \partial q_{B}}=\operatorname{sign}\left(q_{G}^{*}-q_{B}^{*}\right),
\end{aligned}
$$

so that

$$
\frac{\mathrm{d} q_{G}^{*}}{\mathrm{~d} \beta}<0, \quad \frac{\mathrm{d} q_{B}^{*}}{\mathrm{~d} \beta}>0 .
$$

This leads to the following proposition.

Proposition 3 A hike in the degree of environmental ideology leads the brown firm to produce a better environmental quality whereas the green firm chooses to downgrade its environmental quality.

In other words, a more environmentally-friendly population does not incite both firms to choose better environmental qualities. On the contrary, the quality gap shrinks symmetrically around the average quality $\left(q_{G}^{*}+q_{B}^{*}\right) / 2=k^{1 / 2} / 3$. These findings are not straightforward because the industrial organization literature suggests instead that firms have a taste for product differentiation that often leads them to move far apart. However, even though the quality gap shrinks, firms $G$ and $B$ keep selling different qualities.

Consider first the impact of a higher supply of environmentalism $(\beta \uparrow)$ on the equilibrium prices when qualities are given. As the psychic benefits and costs increase with $\beta$, firm $G$ enjoys relatively more market power than firm $B$ because the subjective quality gap $Q_{G}-Q_{B}$ widens with $\beta$. Furthermore, since $c<1$, (5) implies that a change in the quality gap $q_{G}-q_{B}$ is associated with a less than proportional change in the price gap. Moreover, (6) shows that more consumers buy green when the quality gap shrinks $(\bar{\theta} \downarrow)$. Combining these various effects shows that the green firm is incentivized to save on its production cost by reducing its quality. Since the brown firm loses some market power relative to the green firm, the former strives to regain consumers by improving its own quality. Eventually, both the quality and price gaps end up being narrower after the rise in the supply of environmentalism. Hence, more consumers buy brown. It should be clear that the environmental consequences of these changes in firms' strategies are not easy to predict. We may thus 
conclude that firms operating in an environmentally-friendly society may choose unfriendly environmental qualities. ${ }^{8}$

\section{Environmental Surplus and the Market}

The general belief holds that a higher concern about the ecological implications of green consumerism fosters a better environment through more selective consumers' choices. We saw above that this argument is too simplistic. First, it disregards the fact that consumers' choices are also influenced by the prices and qualities of the goods made available on the market. For example, when the brown product is cheaper than the green one, the consumers whose willingness-to-pay is low will purchase the brown one. More importantly, by changing consumers' incentives, environmentalism leads firms to revise their price and quality strategies in a way that need not reduce the carbon footprint generated by the consumption of the goods. That said, does a greener society incentivize firms to choose qualities and prices such that consumers' choices lead to a better ecological footprint? To assess the overall impact of a quality pair $\left(q_{G}, q_{B}\right)$, we use what we call the environmental surplus.

The environmental surplus (ES) measures the environmental impact of the consumption of the green and brown variants at the market outcome. It is defined as the sum of the market shares of the two variants, weighted by the environmental quality of the corresponding product:

$$
E S\left(q_{G}, q_{B}\right) \equiv E G\left(q_{G}, q_{B}\right)+E B\left(q_{G}, q_{B}\right)=\left[1-\bar{\theta}\left(q_{G}, q_{B}\right)\right] \cdot q_{G}+\bar{\theta}\left(q_{G}, q_{B}\right) \cdot q_{B} .
$$

Recall that the best environmental quality is $\bar{q}$ while the worst is 0 . As a result, the environmental surplus is minimized when all consumers purchase the quality $q=0$, whereas $E S$ reaches its highest value when all consumers buy the quality $\bar{q}$. The value of $E S$ always increases when a growing number of consumers buy the green variant. By contrast, the opposite holds when more consumers purchase the brown variant. This highlights the role of the marginal consumer in evaluating the environmental surplus generated by a given quality pair $\left(q_{G}, q_{B}\right)$. Furthermore, when firms change the environmental quality of their products, this has a direct effect on the environmental surplus, but also an indirect impact through the new value of the marginal consumer $\bar{\theta}$ since this one varies with $q_{G}$ and $q_{B}$ according to (13). Consequently, the impact of $\beta$ on $E S$ must account for several distinct effects. $^{9}$

Consider an environmentalist society that evaluates the market outcome through the sole criterion ES. It follows from (13) that more consumers buy brown when $\beta$ rises. Since $q_{G}^{*}$ decreases with $\beta, E G$ thus decreases. As for the brown variant, we have seen that its quality rises. Since the market share of firm $B$ increases, the net impact on $E B$ is positive. In sum, the impact of $\beta$ on $E G$ and $E B$ are opposite. Comparing the variations of $E G$ and $E B$ shows that $|\mathrm{d} E G / \mathrm{d} \beta|>|\mathrm{d} E B / \mathrm{d} \beta|$ holds, which means that $E S$ decreases when the environmental ideology is heightened.

The argument goes as follows. Since the green firm enjoys more significant psychic benefits, it is able to supply a lower quality sold at a higher price. These two effects

\footnotetext{
${ }^{8}$ Note that a higher transportation cost always reduces both qualities in Deltas et al. (2013) by weakening the role of vertical differentiation. This confirms once more that the transportation cost parameter differs from $\beta$.

${ }^{9}$ Note that maximizing the environmental surplus is equivalent to minimizing the environmental damage $E D \equiv \bar{q}-E S$, which is often used in the literature.
} 
incentivize more consumers to shift to brown. In addition, the brown firm supplies a better quality which should attract even more consumers away from firm $G$ despite the higher psychic costs. The combination of all these effects allows firm $B$ to raise its price, but not as much as its rival. The net negative effect on $E G$ dominates the net positive effect on $E B$, so that the environmental surplus associated with the market outcome decreases with $\beta$ (see Appendix B).

Disregarding the costs generated by the supply of environmental qualities seems too extreme. This is why we find it more reasonable to consider the net environmental surplus defined as follows:

$$
\operatorname{NES}\left(q_{G}, q_{B}\right)=E S\left(q_{G}, q_{B}\right)-C\left(q_{G}, q_{B}\right),
$$

where the total cost

$$
C\left(q_{G}, q_{B}\right)=c q_{G}(1-\bar{\theta})+c q_{B} \bar{\theta}+\frac{1}{2} q_{G}^{2}+\frac{1}{2} q_{B}^{2},
$$

is the social cost of producing the qualities $q_{G}$ and $q_{B}$ when the mass of green consumers is $1-\bar{\theta}$ while $\bar{\theta}$ is the mass of brown consumers.

Recall that the average quality $\left(q_{G}^{*}+q_{B}^{*}\right) / 2$ is independent of $\beta$. When $q_{G}^{*}$ decreases by the amount $\Delta>0$ while $q_{B}^{*}$ increases by the same amount, the investment $\operatorname{cost} q_{G}^{2} / 2+q_{B}^{2} / 2$ decreases with $\beta$. Since the environmental surplus and the investment costs vary in the same direction, while $(1-\bar{\theta}) c q_{G}^{*}$ and $\bar{\theta} q_{B}^{*}$ move in opposite directions, the impact of $\beta$ on NES is a priori ambiguous. Nevertheless, Appendix B.1 shows that the net environmental surplus decreases with the supply of environmentalism, i.e., the drop in ES dominates the drop in costs. ${ }^{10}$

Summing up the above results, we have the following proposition.

Proposition 4 If $\beta>k / 3$, then a higher supply of environmentalism worsens the (net) environmental surplus at the market outcome.

The result, which clashes with mainstream pro-environmental claims, tells us something important: a greener society does not trigger a better ecological footprint because firms adjust their qualities in a way that may incite more consumers to purchase the brown variant because its growing market power allows the green firm to reduce its environmental quality.

But what happens to firms' profits when $\beta$ increases? A standard argument borrowed from product differentiation theory would suggest that the impact of $\beta$ on firms' profits is negative because products are less differentiated. Let us show that things are more involved than that. Indeed, using (14) shows that $\mathrm{d} \pi_{B}^{*}\left(q_{G}^{*}, q_{B}^{*}\right) / \mathrm{d} \beta>0$ always holds. However, $\mathrm{d} \pi_{G}^{*}\left(q_{G}^{*}, q_{B}^{*}\right) / \mathrm{d} \beta$ is positive if and only if $\beta>(\sqrt{17}+9) k / 36>\bar{\beta}$. In other words, firm $G$ 's profits first decrease with $\beta$ and, then, increase. Initially, the higher psychic benefits associated with the consumption of the green variant do not endow firm $G$ with enough market power to compensate this firm for the narrower quality gap that favors firm $B$. However, under a sufficiently high supply

\footnotetext{
${ }^{10}$ In the foregoing, we assume that $E S$ and $C$ are directly comparable because consumers know the "true" social value of the environmental qualities. However, in a population formed by individuals having different attitudes toward the environment, finding a consensus on the value of the environment might be problematic. One way out is to consider $\lambda E S-C$ as the environmental surplus where the parameter $\lambda$ is treated as the "shadow price" of environmental qualities. When these ones are endowed with a higher weight than costs $(\lambda>1), \lambda E S$ still decreases with $\beta$ while the drop in $\lambda E S$ still dominates the drop in $C$. Hence, $\lambda E S-C$ decreases with $\beta$ even when $\lambda$ takes on higher values.
} 
of environmentalism, the green firm is always better off. In this case, green consumerism is beneficial to both firms because high psychic benefits and costs make consumers sufficiently heterogeneous to permit firms to charge high prices.

Finally, as for the social welfare performance of the market outcome, we show in the Supplementary Material that it first decreases and, then, increases with environmentalism. Those results highlight once more the need to study how the market selects prices and qualities before evaluating the social desirability of environmentalism.

\section{Environmental Policies}

In a way, the above findings are disappointing. This leads us to consider the following policy instruments: (i) a minimum environmental standard and (ii) the development of green technologies. We discuss their efficiency per se. Furthermore, when combined with these instruments, environmentalism might deliver its expected payoffs. Unless explicitly mentioned, we consider only the case of an interior equilibrium.

\subsection{Minimum Environmental Standard}

Assume that $\beta>\bar{\beta}$, so that the quality equilibrium is interior and given by (10) at the unregulated market outcome. The minimum environmental quality standard (MQS) $Q<q_{G}^{*}$ must be such that $Q>q_{B}^{*}$, for otherwise the MQS would not bind. Assume that the quality equilibrium $\left(q_{G}^{* *}, q_{B}^{* *}\right)$ is such that $q_{B}^{* *}>Q$ when the strategy space of the two firms is given by $[Q, \bar{q}]$. Since $q_{B}^{* *}$ maximizes $\pi_{B}\left(q_{G}^{* *}, q_{B}\right)$ over $[Q, \bar{q}]$ while $\pi_{B}\left(q_{G}^{* *}, q_{B}\right)$ is strictly concave over $[0, \bar{q}], q_{B}^{* * *}$ also maximizes $\pi_{B}\left(q_{G}^{* *}, q_{B}\right)$ over $[0, \bar{q}]$. In this case, there would exist two interior quality equilibria, $\left(q_{G}^{*}, q_{B}^{*}\right)$ and $\left(q_{G}^{* *}, q_{B}^{* *}\right)$, which contradicts Proposition 2. Therefore, in equilibrium, the MQS is not innocuous as it is profit-maximizing for the brown firm to choose a quality equal to $Q$. It then follows from (9) that the green firm chooses the quality

$$
q_{G}^{*}(Q)=\frac{k^{1 / 2}\left(4 \beta-k^{1 / 2} Q\right)}{9 \beta-k},
$$

which is smaller than the quality $q_{G}^{*}$ chosen at the interior equilibrium (10) because qualities are strategic substitutes. Hence, $\left(q_{G}^{*}(Q), Q\right)$ is the only candidate Nash equilibrium of the quality game where the strategy space of the two firms is $[Q, \bar{q}]$. For $\left(q_{G}^{*}(Q), Q\right)$ to be an interior equilibrium, the following conditions must be satisfied: (i) $q_{G}^{*}(Q)>Q$, (ii) $0<\bar{\theta}\left(q_{G}^{*}(Q), Q\right)<1$, and (iii) $\pi_{B}\left(q_{G}^{*}(Q), Q\right)>0$.

$$
\frac{k^{1 / 2}\left(4 \beta-k^{1 / 2} Q\right)}{9 \beta-k}-Q
$$

First, $q_{G}^{*}(Q)>Q$ holds if and only if $Q<4 k^{1 / 2} / 9$. When this condition does not hold, the firm supplying $Q$ becomes the high-quality variant producer. Second, plugging $q_{G}^{*}(Q)$ and $Q$ in (6) yields the marginal consumer

$$
\bar{\theta}\left(q_{G}^{*}(Q), Q\right)=\frac{1}{2} \frac{6 \beta-2 k+3 Q k^{1 / 2}}{9 \beta-k},
$$


which increases with $Q$. Indeed, as $Q$ rises, the quality of the green variant decreases because qualities are strategic substitutes, which makes $B$ more attractive to a wider range of consumers. Clearly, $0<\bar{\theta}\left(q_{G}^{*}(Q), Q\right)<1$ holds if and only if $Q<4 k^{-1 / 2} \beta$. Last, $\pi_{B}\left(q_{G}^{*}(Q), Q\right)>0$ because $\pi_{B}\left(q_{G}^{*}(Q), Q\right)$ increases with $Q$ and $\pi_{B}\left(q_{G}^{*}(0), 0\right)>0$, while (7) implies the green firm's profits decrease in $Q$. Thus, $\left(q_{G}^{*}(Q), Q\right)$ is the unique interior equilibrium of the regulated quality game if $Q$ is not too large or if $\beta$ is sufficiently large.

We may conclude that an MQS raises the quality and profits of the brown firm but lowers those of the green firm, which is reminiscent of Deltas et al. (2013). Although an MQS does not increase the environmental performance of all firms, the average quality $\left(Q+q_{G}^{*}(Q)\right) / 2$ always increases with $Q$ and $\beta$. Recall that the average quality is constant and independent of $\beta$ when the market is unregulated.

We now study the impact of an MQS on the environmental surplus $E S\left(q_{G}^{*}(Q), Q\right)$ :

$$
E S\left(q_{G}^{*}(Q), Q\right)=\frac{1}{2} \frac{27 \beta k^{1 / 2} Q^{2}+\left(2 k^{2}+54 \beta^{2}-48 \beta k\right) Q+48 \beta^{2} k^{1 / 2}}{(9 \beta-k)^{2}},
$$

which is quadratic and convex in $Q$. Solving the first-order condition yields the unique minimizer of ES:

$$
\bar{Q}=\frac{-27 \beta^{2}+24 k \beta-k^{2}}{27 \beta k^{1 / 2}},
$$

which is positive at $\beta=k / 3$ and smaller than $4 k^{1 / 2} / 9$. Since

$$
\bar{Q}>q_{B}^{*} \Leftrightarrow \beta<2 k / 3,
$$

we have the following proposition.

Proposition 5 Over the range $(k / 3,2 k / 3)$, the environmental surplus first decreases with the MQS over $\left(q_{B}^{*}, \bar{Q}\right)$ and, then, increases. If $\beta>2 k / 3$, the environmental surplus increases with the $M Q S$.

The cross-derivative of $E S$ is given by

$$
\frac{\partial^{2} E S}{\partial Q \partial \beta}=-3 k^{1 / 2} \frac{81 Q \beta-54 k^{1 / 2} \beta+9 Q k-2 k^{3 / 2}}{(9 \beta-k)^{3}}>0 .
$$

Indeed, the numerator is negative at $\beta=k / 3$, which is the minimum value of $\beta$, and negative at $Q=4 k^{1 / 2} / 9$, which is the maximum admissible value of $Q$. Since it is increasing in $Q$ and decreasing in $\beta$, the numerator is always negative. That is, the MQS and environmentalism are complements, i.e., environmentalism reinforces the positive effect of an MQS on the environmental surplus associated with the market outcome. In addition, a higher supply of environmentalism allows imposing a stronger MQS.

\subsection{Green Technologies}

It is widely accepted among policy-makers that the use of environmental-friendly technologies is one of the main tools that should permit the development of a green society. Reformulating this idea in our setting amounts to assuming that firms may access a technology that allows them to produce $q_{G}$ and $q_{B}$ at lower costs. We are agnostic about the reasons that explain the 
emergence of this new technology. In this section, our aim is instead to investigate the market and environmental effects of such a technology. More specifically, we consider a cost function that may be viewed as a reduced form for an abatement or replacement technology designed through innovations or governments subsidizes. We consider the following two cases: (i) the new technology reduces the fixed production cost (Ronnen, 1991) and (ii) it reduces the marginal production cost (Crampes and Hollander 1995).

Fixed costs. So far, we have assumed that production costs are given by $c q+q^{2} / 2$. We now assume that the new technology is such that:

$$
F(q)=\frac{q^{2}}{2 \gamma}
$$

where $\gamma>0$ measures the technological greenness of the production technique: the higher $\gamma$, the lower the cost of designing the environmental quality $q$. Since we have normalized $\gamma=1$ in the previous sections, we now study how increasing $\gamma$ above 1 affects the market outcome.

Consider a game prior to the quality game, where each firm chooses either to adopt or not to adopt the $\gamma$-technology. The lemma proven in Appendix C shows that the unique Nash equilibrium is such that both firms choose the greener technology described by (15).

Following the argument of Sect. 4, it can be shown that, for $\beta>\gamma \bar{\beta}$, the equilibrium qualities are given by

$$
q_{G}^{\gamma}=\frac{2 \gamma k^{1 / 2}}{3} \frac{6 \beta-\gamma k}{9 \beta-2 \gamma k}>q_{B}^{\gamma}=\frac{2 \gamma k^{1 / 2}}{3} \frac{3 \beta-\gamma k}{9 \beta-2 \gamma k},
$$

which are identical to (10) when $\gamma=1$. It is readily verified that $q_{G}^{\gamma}$ increases with the degree of technological greenness. As for $q_{B}^{\gamma}$, the argument goes as follows. We have:

$$
\frac{\mathrm{d} q_{B}^{\gamma}}{\mathrm{d} \gamma}=\frac{2}{3} k^{1 / 2} \frac{2 k^{2} \gamma^{2}+9 \beta(3 \beta-2 k \gamma)}{(9 \beta-2 k \gamma)^{2}} .
$$

The numerator of this expression is a quadratic and convex function of $\beta$ which has two positive roots, the brown quality also increases with $\gamma$ when $\beta$ is larger than the larger root given by $0.526 \gamma k>\gamma \bar{\beta}$. Hence, both environmental qualities increase with technological greenness when the supply of environmentalism is sufficiently high. Moreover, the green quality rises faster than the brown one. This is because the strict convexity of the fixed cost function implies that a higher technological greenness has a bigger impact on firm $G$ than on firm $B$.

Furthermore, it must be that

$$
\bar{\theta}\left(q_{G}^{\gamma}, q_{B}^{\gamma}\right)=\frac{3 \beta-\gamma k}{9 \beta-2 \gamma k}>0,
$$

because $\beta>\gamma k / 3$. Differentiating this expression with respect to $\gamma$ shows that the market share of the green variant grows with $\gamma$.

Since the environmental surplus is given by

$$
E S^{\gamma}=\frac{2}{3} k^{1 / 2} \gamma \frac{2 k^{2} \gamma^{2}-18 k \beta \gamma+45 \beta^{2}}{(9 \beta-2 k \gamma)^{2}},
$$

the derivative of $E S$ with respect to $\gamma$ is equal to 


$$
\frac{\mathrm{d} E S^{\gamma}}{\mathrm{d} \gamma}=(15 \beta-2 k \gamma) \frac{2 k^{2} \gamma^{2}-12 k \beta \gamma+27 \beta^{2}}{(9 \beta-2 k \gamma)^{3}},
$$

which is positive for all $\beta$ and $\gamma$.

Last, the effect on the net environmental surplus is also positive. Indeed, we have:

$$
N E S^{\gamma}=\frac{2}{9} \frac{k \gamma(3-k)\left(2 k^{2} \gamma^{2}+9 \beta(5 \beta-2 k \gamma)\right)}{(9 \beta-2 k \gamma)^{2}},
$$

so that

$$
\frac{\mathrm{d} N E S^{\gamma}}{\mathrm{d} \gamma}=\frac{2}{9} k(3-k)(15 \beta-2 k \gamma) \frac{2 k^{2} \gamma^{2}+27 \beta^{2}-12 k \beta \gamma}{(9 \beta-2 k \gamma)^{3}}>0 .
$$

Observe that

$$
\frac{\partial^{2} E S^{\gamma}}{\partial \beta \partial \gamma}<0
$$

Hence, environmentalism weakens the positive effects of green technologies.

Marginal quality cost. We now investigate to the impact of a lower marginal quality cost. Since $k$ decreases with $c$, a lower marginal quality cost amounts to a higher $k$.

Assume first that $\beta>\bar{\beta}$. Differentiating (10) with respect to $k$ yields:

$$
\frac{\mathrm{d} q_{G}^{*}}{\mathrm{~d} k}=\frac{1}{3 k^{1 / 2}} \frac{54 \beta^{2}-15 k \beta+2 k^{2}}{(9 \beta-2 k)^{2}}, \quad \frac{\mathrm{d} q_{B}^{*}}{\mathrm{~d} k}=\frac{1}{3 k^{1 / 2}} \frac{(3 \beta-2 k)(9 \beta-k)}{(9 \beta-2 k)^{2}} .
$$

The sign of $\mathrm{d} q_{G}^{*} / \mathrm{d} k$ is given by the sign of the numerator, which is a convex parabola of $k$. This parabola is positive at $k=0$ and its minimum is reached at $k=15 / 4 \beta$. Plugging this value in the numerator shows that this one is always positive. Therefore, the green quality increases with $k$. As for the brown quality, $\mathrm{d} q_{B}^{*} / \mathrm{d} k$ is negative when $k / 3<\beta<2 k / 3$ and positive for $\beta>2 k / 3$. Consequently, when $\beta>2 k / 3$, both qualities rise when the marginal quality cost decreases.

Differentiating (13) with respect to $k$ shows that more consumers buy the brown quality when $k$ increases $(\bar{\theta} \uparrow)$. Nevertheless, it is easy to show that a lower marginal quality cost leads to a higher environmental surplus, while the net environmental surplus also increases with $k$. However, a higher supply of environmentalist reduces this positive effect.

Summarizing yields the following proposition.

Proposition 6 A greener technology leads to a better environmental outcome. However, a higher supply of environmentalism reduces the magnitude of these positive effects.

\section{Concluding Remarks}

Green consumerism is often presented as one of the main backbones of new environmental policies. However, very little is known about its impact on firms' decisions. The issue is important because greener preferences affect firms' market power, and thus the market outcome. This paper contributed to reduce such a lacuna. To this end, we have developed 
a parsimonious model that considers the psychic costs and benefits associated with the production and consumption of goods that generate different amounts of emissions. Using this setting has allowed us to show that environmental ideology is effective in curbing the damages generated by polluting products in a market economy when the high-quality firm supplies the brown product while it is ineffective when the green product is also the highquality good. Is, then, the pursuit of green consumerism futile? Not at all. First, our analysis suggests that public policies should help the low-quality products, which are also the cheapest ones, to become greener than their rivals. Second, environmentalism can be combined with other and more traditional policy tools. In other words, our findings suggest the need for policy initiatives that add to those aimed at promoting environmentalism. Here too, care is needed. Indeed, although a higher supply of environmentalism reinforces the positive effects of a minimum environmental standard, it weakens those of a greener technology. The combination of various tools affects their environmental performance in ways that are not easy to predict when firms behave strategically. Clearly, more work is called for.

\section{Appendix A: Proof of Proposition 2}

In what follows we consider first the leapfrogging of firm $B$ and, then, that of firm $G$.

1. Let $\Pi_{B}^{l p f}\left(q_{G}^{*}, q_{B p f}^{l p f}\right)$ be the profit of firm $B$ when it leapfrogs firm $G$ from above by supplying the quality $q_{B}^{p p f}=\mu q_{G}^{*}$ with $\mu \geq 1$. The profit of firm $B$ is then given by

$$
\Pi_{B}^{l p f}\left(\mu q_{G}^{*}, q_{G}^{*}\right)=\frac{\left(4 \beta+k^{1 / 2}\left(\mu q_{G}^{*}-q_{G}^{*}\right)\right)^{2}}{18 \beta}-\frac{1}{2}\left(\mu q_{G}^{*}\right)^{2}-H .
$$

Differentiating $\Pi_{B}^{l p f}\left(\mu q_{G}^{*}, q_{G}^{*}\right)$ with respect to $\mu$ and plugging $q_{G}^{*}$, we obtain:

$$
\frac{\partial \Pi_{B}^{l p f}\left(\mu q_{G}^{*}, q_{G}^{*}\right)}{\partial \mu}=\frac{4\left[54 \beta^{2}-\mu(6 \beta-k)(9 \beta-k)-k(18 \beta-k)\right](6 \beta-k) k}{81 \beta(9 \beta-2 k)^{2}}
$$

whose sign is the sign of

$$
54 \beta^{2}-\mu(6 \beta-k)(9 \beta-k)-k(18 \beta-k),
$$

which is linearly decreasing in $\mu$ and equal zero when

$$
\mu=\frac{18 \beta(3 \beta-k)+k^{2}}{(9 \beta-k)(6 \beta-k)}<1 .
$$

Therefore, under leapfrogging, firm $B$ 's highest profit is obtained when $\mu \rightarrow 1$ from above. Plugging $q_{G}^{*}$ in (A.1) and $\mu=1$ yields:

$$
\left.\Pi_{B}^{l p f}\right|_{\mu=1}=\frac{2}{9} \frac{324 \beta^{3}-180 \beta^{2} k+28 \beta k^{2}-k^{3}}{(9 \beta-2 k)^{2}}-H .
$$

Using $\pi_{B}^{*}\left(q_{G}^{*}, q_{B}^{*}\right)$, it is readily verified that

$$
\left.\Pi_{B}^{l p f}\right|_{\mu=1}-\pi_{B}^{*}\left(q_{G}^{*}, q_{B}^{*}\right)=\frac{2 \beta}{9} \frac{243 \beta^{2}-117 k \beta+13 k^{2}}{(9 \beta-2 k)^{2}}-H,
$$


which is negative if and only if

$$
H>H_{\min } \equiv \frac{2 \beta}{9} \frac{243 \beta^{2}-117 k \beta+13 k^{2}}{(9 \beta-2 k)^{2}} .
$$

2. We now show that firm $G$ has no incentive to supply a quality $m q_{B}^{*}$ with $m \leq 1$, thereby becoming the low-quality firm.

Let $\Pi_{G}^{l p f}\left(q_{G f}^{l p f}, q_{B}^{*}\right)$ be the profit of firm $G$ when it leapfrogs firm $B$ from below by supplying the quality $q_{G}^{p f}=m q_{B}^{*}$ with $m \leq 1$. The profit of firm $G$ is then as follows:

$$
\Pi_{G}^{l p f}\left(m q_{B}^{*}, q_{B}^{*}\right)=\frac{1}{18 \beta}\left(2 \beta-k^{1 / 2}\left(q_{B}^{*}\right)^{2}(1-m)^{2}-9 \beta m^{2}\left(q_{B}^{*}\right)^{2}\right) .
$$

Differentiating (A.3) with respect to $m$ yields:

$$
2\left(q_{B}^{*}\right)^{2}\left(9 m \beta-k^{1 / 2} m+k^{1 / 2}\right) \geq 18 \beta m\left(q_{B}^{*}\right)^{2}>0,
$$

since $m \in[0,1]$. Therefore, $\Pi_{G}^{l p f}\left(m q_{B}^{*}, q_{B}^{*}\right)$ is increasing in $m$, so that $m=1$ is firm $G$ 's best-leapfrogging-strategy.

Plugging $q_{B}^{*}$ in (A.2) when $m=1$ yields

$$
\left.\Pi_{G}^{l p f}\right|_{m=1}=\frac{2}{9} \frac{\left(9 \beta^{2}(9 \beta-5 k)-k^{3}+10 k^{2} \beta\right)}{(9 \beta-2 k)^{2}} .
$$

Hence, we have

$$
\pi_{G}^{*}\left(q_{G}^{*}, q_{B}^{*}\right)-\left.\Pi_{G}^{l p f}\right|_{m=1}=\frac{2}{9} \beta \frac{243 \beta^{2}-99 k \beta+11 k^{2}}{(9 \beta-2 k)^{2}}-H,
$$

which is positive if

$$
H<\frac{2 \beta}{9} \frac{243 \beta^{2}-99 k \beta+11 k^{2}}{(9 \beta-2 k)^{2}} \equiv H_{\max } .
$$

It is straightforward to check that

$$
H_{\max }-H_{\min }=\frac{4 \beta k}{9} \frac{9 \beta-k}{(9 \beta-2 k)^{2}}>0
$$

and

$$
H_{\max }<\pi_{G}^{*}\left(q_{G}^{*}, q_{B}^{*}\right)-\pi_{B}^{*}\left(q_{G}^{*}, q_{B}^{*}\right),
$$

thus implying that this range is non-empty.

To sum up, when $H_{\min } \leq H \leq H_{\max }$, no firm has an incentive to leapfrog its rival.

\section{Appendix B: The (net) Environmental Surplus}

In this appendix, we provide the main expressions used to prove the results of Sect. 5.

Consider an interior equilibrium $(\beta>\bar{\beta})$. The value of the environmental surplus at the equilibrium outcome is given by the following expression: 


$$
E S\left(q_{G}^{*}, q_{B}^{*}\right)=\frac{2 k^{1 / 2}}{3} \frac{45 \beta^{2}-37 k \beta+8 k^{2}}{(9 \beta-4 k)^{2}} .
$$

Differentiating w.r.t. $\beta$ yields:

$$
\frac{\mathrm{d} E S}{\mathrm{~d} \beta}=-\frac{2 k^{3 / 2}}{3} \frac{27 \beta-4 k}{(9 \beta-4 k)^{3}}<0 .
$$

As for the net surplus, it is given by

$$
\operatorname{NES}\left(q_{G}^{*}, q_{B}^{*}\right)=\frac{2 k}{9} \frac{90 \beta^{2}-75 \beta k+16 k^{2}}{(9 \beta-4 k)^{2}} .
$$

Differentiating NES w.r.t. $\beta$ yields:

$$
\frac{\mathrm{d} N E S}{\mathrm{~d} \beta}=-\frac{2 k^{2}}{3} \frac{(15 \beta-4 k) k^{2}}{(9 \beta-4 k)^{3}}<0 .
$$

Likewise, differentiating NES w.r.t. $k$ yields:

$$
\frac{\mathrm{d} N E S}{\mathrm{~d} k}=\frac{4}{9}(3 \beta-k) \frac{-120 k \beta+135 \beta^{2}+32 k^{2}}{(9 \beta-4 k)^{3}},
$$

which is positive for all $\beta>0$.

\section{Appendix C: Lemma}

Lemma In the $2 \times 2$ game where firms chooses between the old and new technologies, adopting the new technology is a dominant strategy for each firm.

We know from (14) that

$$
\pi_{G}\left(q_{G}^{*}, q_{B}^{*}\right)=\frac{2}{9} \frac{(9 \beta-k)(6 \beta-k)^{2}}{(9 \beta-2 k)^{2}}, \quad \pi_{B}\left(q_{G}^{*}, q_{B}^{*}\right)=\frac{2}{9} \frac{(9 \beta-k)(3 \beta-k)^{2}}{(9 \beta-2 k)^{2}}
$$

while it is readily verified that

$$
\pi_{G}^{\gamma}\left(q_{G}^{\gamma}, q_{B}^{\gamma}\right)=\frac{2}{9} \frac{\left(9 \beta-k \gamma^{2}\right)(6 \beta-k \gamma)^{2}}{(9 \beta-2 k \gamma)^{2}}, \quad \pi_{B}^{\gamma}\left(q_{G}^{\gamma}, q_{B}^{\gamma}\right)=\frac{2}{9} \frac{\left(9 \beta-k \gamma^{2}\right)(3 \beta-k \gamma)^{2}}{(9 \beta-2 k \gamma)^{2}}
$$

Assume that firm $G$ adopts the new technology whereas firm $B$ does not. Then, profits are defined by

$$
\pi_{G}^{\gamma}\left(q_{G}, q_{B}\right)=\frac{\left(4 \beta+k^{1 / 2}\left(q_{G}-q_{B}\right)\right)^{2}}{18 \beta}-\frac{1}{2 \gamma} q_{G}^{2}, \quad \pi_{B}^{*}\left(q_{G}, q_{B}\right)=\frac{\left(2 \beta-k^{1 / 2}\left(q_{G}-q_{B}\right)\right)^{2}}{18 \beta}-\frac{1}{2} q_{B}^{2} .
$$

Applying the FOCs yields the following equilibrium qualities: 


$$
q_{G}^{\gamma}=\frac{2 \gamma k^{1 / 2}}{3} \frac{6 \beta-k}{9 \beta-k(\gamma+1)}, \quad q_{B}^{*}=\frac{2 k^{1 / 2}}{3} \frac{3 \beta-k \gamma}{9 \beta-k(\gamma+1)} .
$$

Plugging $q_{G}^{\gamma}$ and $q_{B}^{*}$ into (C.1), we obtain

$$
\pi_{G}^{\gamma}\left(q_{G}^{\gamma}, q_{B}^{*}\right)=\frac{2}{9} \frac{(6 \beta-k)^{2}(9 \beta-k \gamma)}{(9 \beta-k(\gamma+1))^{2}}, \quad \pi_{B}^{*}\left(q_{G}^{\gamma}, q_{B}^{*}\right)=\frac{2}{9} \frac{(9 \beta-k)(3 \beta-k \gamma)^{2}}{(9 \beta-k(\gamma+1))^{2}} .
$$

Firm $B$ prefers to select the new technology $(\gamma>1)$ rather than sticking to the old technology $(\gamma=1)$ :

$$
\pi_{B}^{\gamma}\left(q_{G}^{\gamma}, q_{B}^{\gamma}\right)-\pi_{B}^{*}\left(q_{G}^{\gamma}, q_{B}^{*}\right)=\frac{(9 \beta-k \gamma)(9 \beta-k(\gamma+1))^{2}-(9 \beta-k)(9 \beta-2 k \gamma)^{2}}{(9 \beta-2 k \gamma)^{2}(9 \beta-k(\gamma+1))^{2}}>0 .
$$

Indeed, the denominator of this expression is always positive and strictly decreasing in $\gamma$, while the numerator is equal to 0 for $\gamma=1$ and increasing in $\gamma$ for $\gamma>1$. This implies that $\pi_{B}^{\gamma}\left(q_{G}, q_{B}\right)-\pi_{B}^{*}\left(q_{G}, q_{B}\right)=0$ at $\gamma=0$ and increases in $\gamma$. Consequently, (C.3) is positive and increasing for all $\gamma>1$. In other words, when firm $G$ adopts the new technology, firm $B$ finds it profitable to do the same.

Similarly, the equilibrium profits when firm $B$ adopts the new technology and firm $G$ does not are given by

$$
\pi_{G}^{*}\left(q_{G}^{*}, q_{B}^{\gamma}\right)=\frac{2}{9} \frac{(9 \beta-k)(6 \beta-k \gamma)^{2}}{(9 \beta-k(\gamma+1))^{2}}, \quad \pi_{B}^{\gamma}\left(q_{G}^{*}, q_{B}^{\gamma}\right)=\frac{2}{9} \frac{(3 \beta-k)^{2}(9 \beta-k \gamma)}{(9 \beta-k(\gamma+1))^{2}} .
$$

Firm $G$ 's profit difference between adopting and not adopting the new technology when firm $B$ adopts the new technology is given by

$$
\pi_{G}^{\gamma}\left(q_{G}^{\gamma}, q_{B}^{\gamma}\right)-\pi_{G}^{*}\left(q_{G}^{*}, q_{B}^{\gamma}\right)=\frac{(9 \beta-k \gamma)(9 \beta-k(\gamma+1))^{2}-(9 \beta-k)(9 \beta-2 k \gamma)^{2}}{(9 \beta-2 k \gamma)^{2}(9 \beta-k(\gamma+1))^{2}}>0 .
$$

Repeating the above argument shows that $\pi_{G}^{\gamma}\left(q_{G}^{\gamma}, q_{B}^{\gamma}\right)-\pi_{G}^{*}\left(q_{G}^{*}, q_{B}^{\gamma}\right)>0$ for all $\gamma>1$. In other words, it is not optimal for firm $G$ to stick to the old technology when firm $B$ adopts this technology.

Consider now the $2 \times 2$ game where the two firms possess two strategies, either to adopt (A) or not to adopt (NA).

\begin{tabular}{|c|c|c|}
\hline$G \backslash B$ & $A$ & $N A$ \\
\hline$A$ & $\pi_{G}^{\gamma}\left(q_{G}^{\gamma}, q_{B}^{\gamma}\right), \pi_{B}^{\gamma}\left(q_{G}^{\gamma}, q_{B}^{\gamma}\right)$ & $\pi_{G}^{\gamma}\left(q_{G}^{\gamma}, q_{B}^{*}\right), \pi_{B}^{*}\left(q_{G}^{\gamma}, q_{B}^{*}\right)$ \\
\hline$N A$ & $\pi_{G}^{*}\left(q_{G}^{*}, q_{B}^{\gamma}\right), \pi_{B}^{\gamma}\left(q_{G}^{*}, q_{B}^{\gamma}\right)$ & $\pi_{G}^{*}\left(q_{G}^{*}, q_{B}^{*}\right), \pi_{B}^{*}\left(q_{G}^{*}, q_{B}^{*}\right)$ \\
\hline
\end{tabular}

Using (C.2) and (14) imply

$$
\begin{aligned}
\pi_{B}^{\gamma}\left(q_{G}^{*}, q_{B}^{\gamma}\right) & >\pi_{B}^{*}\left(q_{G}^{*}, q_{B}^{*}\right) \\
& \Leftrightarrow \frac{2}{9} \frac{(3 \beta-k)^{2}(9 \beta-k \gamma)}{(9 \beta-k(\gamma+1))^{2}}>\frac{2}{9} \frac{(9 \beta-k)(3 \beta-k)^{2}}{(9 \beta-2 k)^{2}} \\
& \Leftrightarrow k(\gamma-1) \frac{9 \beta(9 \beta-k(\gamma+1))+k^{2}(\gamma-1)}{(2 k-9 \beta)^{2}(k-9 \beta+k \gamma)^{2}}>0 .
\end{aligned}
$$


Similarly, (C.4) and (14) imply

$$
\begin{aligned}
\pi_{G}^{\gamma}\left(q_{G}^{\gamma}, q_{B}^{*}\right) & >\pi_{G}^{*}\left(q_{G}^{*}, q_{B}^{*}\right) \\
& \Leftrightarrow \frac{2}{9} \frac{(6 \beta-k)^{2}(9 \beta-k \gamma)}{(9 \beta-k(\gamma+1))^{2}}>\frac{2}{9} \frac{(9 \beta-k)(6 \beta-k)^{2}}{(9 \beta-2 k)^{2}} \\
& \Leftrightarrow \frac{2}{9} k(k-6 \beta)^{2}(\gamma-1) \frac{9 \beta(9 \beta-k(\gamma+1))+k^{2}(\gamma-1)}{(9 \beta-2 k)^{2}(9 \beta-k(\gamma+1))^{2}}>0 .
\end{aligned}
$$

It then follows from (C.3), (C.5), (C.6), and (C.7) that $A$ is a dominant strategy for each player.

Supplementary Information The online version contains supplementary material available at https://doi. org/10.1007/s10640-022-00655-4.

Acknowledgements We are greteful to the editor and two referees for numerous insightful comments and suggestions. We also thank S. Ambec, H. Bar-Isaac, Ph. De Donder, J. Gabszewicz, G. Grolleau, L. Lambertini, A. Mantovani, S. Proost, F. Sanna Randaccio, S. Zanaj, and participants at the Second Workshop in Industrial Economics in Aveiro for helpful discussions and remarks. The third author acknowledges the suppport of the HSE University Basic Research Program.

Funding Open access funding provided by Università degli Studi di Roma La Sapienza within the CRUICARE Agreement.

Open Access This article is licensed under a Creative Commons Attribution 4.0 International License, which permits use, sharing, adaptation, distribution and reproduction in any medium or format, as long as you give appropriate credit to the original author(s) and the source, provide a link to the Creative Commons licence, and indicate if changes were made. The images or other third party material in this article are included in the article's Creative Commons licence, unless indicated otherwise in a credit line to the material. If material is not included in the article's Creative Commons licence and your intended use is not permitted by statutory regulation or exceeds the permitted use, you will need to obtain permission directly from the copyright holder. To view a copy of this licence, visit http://creativecommons.org/licenses/by/4.0/.

\section{References}

Allcott B (2005) Jevons' paradox. Ecol Econ 54:9-21

Amacher GS, Koskelac E, Ollikainend M (2004) Environmental quality competition and eco-labeling. J Environ Econ Manage 47:284-306

Ambec S, De Donder P (2021) Environmental policy with green consumerism. J Econ Manage Strategy, forthcoming

Anderson SP, de Palma A, Thisse J-F (1992) Discrete choice theory of product differentiation. MIT Press, Cambridge, MA

Andreoni J (1990) Impure altruism and donations to public goods: a theory of warm-glow giving. Econ J 100:464-77

Andreoni J (1995) Warm-glow versus cold-prickle: the effects of positive and negative framing on cooperation in experiments. Q J Econ J 110:1-21

Bansal S, Gangopadhyay S (2003) Tax/subsidy policies in the presence of environmentally aware consumers. J Environ Econ Manage 45:333-55

Bonroy O, Constantatos C (2015) On the economics of labels: how their introduction affects the functioning of markets and the welfare of all participants. Am J Agric Econ 97:239-59

Brécard D (2013) Environmental quality competition and taxation in the presence of green network effect among consumers. Environ Resour Econ 54:1-19

Brekke KR, Nuscheler R, Straume OR (2006) Quality and location choices under price regulation. J Econ Manage Strategy 15:207-27 
Carlsson F, García JH, Löfgren $\AA$ (2010) Conformity and the demand for environmental goods. Environ Resour Econ 47:407-21

Crampes C, Hollander A (1995) Duopoly and quality standards. Eur Econ Rev 39:71-82

Deltas G, Harrington DR, Khanna M (2013) Oligopolies with (somewhat) environmentally conscious consumers: market equilibrium and regulatory intervention. J Econ Manage Strategy 22:640-67

Dosi C, Moretto M (2001) Is eco-labelling a reliable environmental policy measure? Environ Resour Econ 18:113-27

Egbue O, Long S (2012) Barriers to widespread adoption of electric vehicles: an analysis of consumer attitudes and perceptions. Energy Policy 48:717-29

Eriksson C (2004) Can green consumerism replace environmental regulation?-A differentiated-products example. Resour Energy Econ 26:281-93

Farrow K, Grolleau G, Ibanez L (2017) Social norms and pro-environmental behavior: a review of the evidence. Ecol Econ 140:1-13

Gabszewicz JJ, Thisse J-F (1979) Price competition, quality, and income disparities. J Econ Theory 20:340-359

García-Gallego A, Georgantzís N (2009) Market effects of changes in consumers' social responsibility. J Econ Manage Strategy 18:235-62

Garella PG, Lambertini L (2014) Bidimensional vertical differentiation. Inter J Ind Organ 32:1-10

Glaeser E (2014) The supply of environmentalism: psychological interventions and economics. R Environ Econ Policy 8:208-29

Grolleau G, Ibanez L, Mzoughi N (2009) Too much of a good thing? why altruism can harm the environment? Ecol Econ 68:2145-49

Irmen A, Thisse J-F (1998) Competition in multi-characteristics spaces: Hotelling was almost right. J Econ Theory $78: 76-102$

Kahn ME (2007) Do greens drive hummers or hybrids? environmental ideology as a determinant of consumer choice. J Environ Econ Manage 54:129-45

Millner A, Ollivier H (2012) Beliefs, politics, and environmental policy. R Environ Econ Policy 10:226-44

Moraga-Gonzalez JL, Padron-Fumero N (2002) Environmental policy in a green market. Environ Resour Econ 22:419-47

Motta M (1993) Endogenous quality choice: price vs. quantity competition. J Ind Econ 41:113-31

Nyborg K (2018) Social norms and the environment. Annu. Rev. Resour. Econ 10:405-23

Lahmandi-Ayed R (2007) Finiteness property with vertical and horizontal differentiation: does it really matter? Econ Theory 33:531-48

Shaked A, Sutton J (1983) Natural oligopolies. Econometrica 51:1469-83

Sorrell S (2009) Jevon's Paradox revisited: the evidence for backfire from improved efficiency. Energy Policy $37: 1456-69$

Stigler GJ, Becker GS (1977) De gustibus non est disputandum. Amer Econ Rev 67:76-90

van't Veld K (2020) Eco-labels: modeling the consumer side. Annu Rev Resour Econ 12:187-207

Vivanco DF, Kemp R, van der Voet E (2016) How to deal with the rebound effect? a policy-oriented approach. Energy Policy 94:114-25

Yenipazarli A (2015) The economics of eco-labelling: standards and prices. Int J Prod Econ 170:275-86

Publisher's Note Springer Nature remains neutral with regard to jurisdictional claims in published maps and institutional affiliations. 